
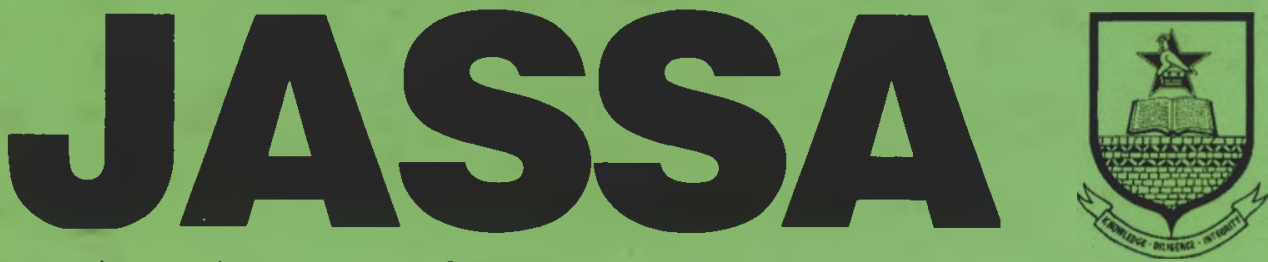

Journal of Applied Science in Southern Africa

The Journal of the University of Zimbabwe

Volume 4, Number 2, 1998

ISSN 1019-7788

\title{
CONTENTS
}

Editorial

A pedestrian route to Gleason's theorem

S.A. Mutangadura

Modified two-step potential model: Heavy mesons

L. K. Sharma, P. K. Jain and V. R. Mundembe

The physics of blackbody radiation: A review

Pushpendra K. Jain and Lalit K. Sharma

The manipulation of irrigation and drying-off schedules of sugar cane to increase sucrose yields

T. Mushipe, C. Chiduza and B.V. Maasdorp

Agronomic practices, major crops and farmers' perceptions of the importance of good stand establishment in Musikavanhu Communal Area, Zimbabwe.

W. Chivasa, D. Harris, C. Chiduza, P. Nyamudeza and A.B. Mashingaidze

Inaugural lecture - New directions for pesticide use.

D.P. Giga

Book Review

Lecture Notes on Pharmacodynamics

Instructions to Authors 


\section{EDITORIAL BOARD}

\section{EDITOR-IN-CHIEF}

Professor C. F. B. Nhachi

\section{DEPUTY EDITOR}

Professor M. F. Zaranyika

\section{EDITORIAL BOARD MEMBERS}

Professor A. Zingoni

(Zimbabwe)

DrM. Chirenje

(Zimbabwe)

Dr P. M. Mashava

(Zimbabwe)

DrD.T. Mukwedeya

(Zimbabwe)

Professor D. P. Giga

(Zimbabwe) 


\section{EDITORIAL}

The seven articles in this issue Volume $4(2)$, consist of three research papers from physics, two research papers from the agricultural sciences, one inaugural lecture and one book review. The current issue has a very good balance of the physical and biological sciences. This is important and in line with the policy of JASSA, that is, the publication of papers on applied sciences. Previously there has been a preponderance of papers from the agricultural sciences. In this issue, the three submissions from the discipline of physics has, for the moment ended that tradition. This is a welcome development as this widens our latitude of papers on applied sciences. The two agro-based papers present particularly interesting findings because of their relevance to the Southern African regional context, in as far as the economic importance of sugar production, both for export and local consumption, and the significance of semi-arid agriculture in the region.

The paper on sugar cane establishes that induction of mild stress, in the form of restriction of water to levels that do not fall below crop factor $(0.85$, increases sucrose yield. The second agricultural based paper establishes poor crop establishment as a major factor affecting crop production in the semi-arid areas of Zimbabwe. Agriculturalists in semi-ard areas will tind this paper interesting. 'A pedestrian route to Gleason's theorem' is the creative title of one of the physics papers. The author here offers what he calls an elementary proof of the 'theorem' and one which is different from those previously offered and it in interesting.

'The inaugural lecture is this issue: 'New Directions for Pesticide Lse' is the first in this series. This lecture is an intellectual plea for the serious consideration of 'the middle road' approach to Integrated Pest Management from a prominent crop scientist. It is argued that the misconception that pests can be eradicated rather controlled has subsequently led to the pesticide treadmill and that the proper use of perticides should involve a thorough understanding of pest population dynamics and how this is influenced by the pesticidal control and the infestation /yiteld loss relationship and the economics of pesticide use. The Integrate Pest Management approach is argued for, convincingly.

Finally the review of the book Lecture Notes on Phommiodymamics represents almost exclusively the first review ever in the JASSA of an article from the medical Giences. This is a welcome development, even more so for the fact that this is a text book for students of the medical sciences.

C. F. B. Nhachi

Editor-in-Chief 


\section{JASSA}

Journal of Applied Science in Southern Africa

The Journal of the University of Zimbabwe

\section{CONTENTS}

A pedestrian route to Gleason's theorem

Modified two-step potential model: Heavy mesons

The physics of blackbody radiation: A review

The manipulation of irrigation and drying-off schedules of sugar cane to increase sucrose yields

Agronomic practices, major crops and farmers' perceptions of the importance of good stand establishment in Musikavanhu Communal Area, Zimbabwe.

Inaugural lecture - New directions

for pesticide use.

D.P. Giga

T. Mushipe, C. Chiduza and B.V. Maasdorp

W. Chivasa, D. Harris, C. Chiduza, $P$. Nyamudeza and

A.B. Mashingaidze 108

Book Review

Instructions to Authors

(C) University of Zimbabwe 1998

Published by University of Zimbabwe Publications

P.O. Box MP203, Mount Pleasant, Harare, Zimbabwe

Typeset by University of Zimbabwe Publications

Printed by Mazongororo Paper Converters 


\title{
Agronomic practices, major crops and farmers' perceptions of the importance of good stand establishment in Musikavanhu Communal Area, Zimbabwe.
}

\author{
W. Chivasa1, D. Harris², C. Chiduza ${ }^{3}$, \\ P. Nyamudeza ${ }^{1}$ and A.B. Mashingaidze ${ }^{3}$ \\ 'Save Valley Experiment Station, P. Bag 2037, Chipinge. Zimbiave \\ ${ }^{2}$ Centre for Arid Zone Studies, University of Wales, Bangor, Gwynedis. LL57 2UW, UK \\ ${ }^{3}$ Department of Crop Science, Faculty of Agriculture, University of Zimbabwe, \\ P. O. Box MP 167, Mount Pleasant, Harare, Zimbabwe
}

\begin{abstract}
Surveys were conducted of rainfed crops growing in farmers' fields in the Musikavanhu Communal Area in Natural Region $V$ of Zimbabwe during and after the 1995/96 cropping season. The major crops were sorghum, maize and sunflower grown by 94.36 and 15 per cent of the farmers, respectively, and occupied 82.12 and seven per cent of the land. Eleven sorghum cultivars were grown in the area during the 1295/96 season, although only four were grown by more than 10 per cent of the farmers. The most popular maize variety was grown by 28 per cent of farmers on 10 per cent of the land, but had been distributed as part of a drought relief package. Stand establishment was identified as a major crop production constraint in this area. More than 50 per cent of the farmers gap-filled at least once and there was a good correlation $\left(R^{2}=0.73\right)$ between frequency of re-sowing of sorghum and the number of varieties present in fields because seed of the initial, preferred variety was not available for later sowings. On-farm seed priming was fairly common in maize and transplanting, using thinnings, was almost universal in sorghum.
\end{abstract}

Keywords: semi-arid Zimbabwe, farmer survey, crop establishment, sorghum, maize, sunflower, seed priming, transplanting.

Introduction

Zimbabwe is classified into five Natural Regions (NR I to V) according to Vincent and Thomas (1960). The agricultural potential of the country declines from NR I which represents the high altitude wet areas to NR V which receives low and erratic rainfall averaging $500 \mathrm{~mm}$ or less per annum. Natural Region V covers 27 per cent of the geographical area of Zimbabwe and 29 per cent of that area is settled by communal farmers (Whitlow, 1980; Anderson et al, 1993). According to Beets (1990), communal farmers are smallholders with small farms (0.5 to 5.0 ha) operated by one or a few households. The head of the farm is usually the head of the household and is sometimes the owner of the farm but is in most cases a tenant 
because there are no title deeds. Most of the smallholders (communal farmers) in Zimbabwe operate under rainfed conditions.

Sorghum, pearl millet and maize are major rainfed crops in NR V and crop failures are common in all crops (Chiduza, 1987; 1993; Chivasa, 1995). Some parts of NR V are very remote and seed is often in short supply, which can result in reductions in area planted and consequently to shortfalls in food supply at household level (Chiduza, et al, 1994). FSRU (1994) found, for example, that in Chivi communal area sorghum hectarage was reduced to just two per cent due to a lack of seeds. Farmers have difficulties in sourcing seed due to persistent droughts and low yields. Whatever grain is harvested has to be eaten and there are few chances to retain seed for planting (van Oosterhout, 1996a).

Crop stand establishment is a major constraint affecting smallholder food production in the semi-arid areas of Zimbabwe. Olver (1988) indicated that one of the major constraints of smallholder maize production in semi-arid areas is the establishment of optimum, even plant populations. Work by Chiduza et al (1995) in the semi-arid Siabuwa communal area confirmed erratic crop establishment as plant population densities in sorghum ranged from 22000 to 160000 plants per ha with a mean of 58700 . Yet farmers planted 1200000 to 1800000 seeds per ha, implying only two to nine per cent germination and emergence. Landsberg (1964) recommended a plant population of around 100000 plants per ha for sorghum for parts of Zimbabwe with rainfall similar to Siabuwa. In the semi-arid south-east lowveld where rainfall is slightly lower than that in Siabuwa in the north-west, recommendations of up to 66000 and 22000 plants per ha for sorghum and maize, respectively, were made by Nyamudeza $(1993,1996)$. Poor crop establishment has also been recorded in the south-east lowveld (Chivasa, 1995). Thus, the problem of poor crop establishment is widespread in Zimbabwe's semi-arid smallholder sector.

Previous work by Harris $(1992,1996)$ in semi-arid Botswana showed that crop stand establishment was poor in about 40 per cent of sowings. Other authors have noted a similar frequency of need to replant in Zimbabwe, with consequent increased labour costs and exhaustion of seed supplies (Chiduza, 1987, 1993, Chiduza et al, 1995; Chivasa, 1995; van Oosterhout, 1996b). In terms of growth and yield, the consequences of poor crop establishment are not confined to wastage of resources because of sub-optimal plant population densities or heterogenous distribution of plants within fields. Surviving plants in a poorly-established stand seldom get off to a good start (Okonwo and Vanderlip, 1985; Harris, 1996).

Two surveys were conducted in four villages in Musikavanhu Communal Area during and after the 1995/96 cropping season. The objectives of the two surveys were: to quantify the various crops that farmers were growing; to test the hypothesis that poor crop establishment was a major constraint on yield; and to gather data on indigenous methods of improving stand establishment. In the first survey the characteristics of the major crops grown in the area were identified and reasons for farmers' choices were recorded, together with information on sowing practices. 
The second survey looked in more detail at farmers' views on, and knowledge of, interventions to improve stand establishment. Improving agronomic management will improve food security of smallholder farmers in marginal areas.

\section{Materials and Methods}

Both surveys were conducted in four villages (Kondo, Maronga, Musa-pingura and Mwacheta) in Musika-vanhu communal area, Chipinge district in the south east lowveld of Zimbabwe (Lat. $20^{\circ} 25^{\prime} \mathrm{S}$, Long. $32^{\circ} 20^{\prime} \mathrm{E}$ ). Mean maximum and minimum temperatures of the area are shown in figure 1a. Long-term averages of monthly rainfall and potential evapotranspiration (PET) clearly show the marginal status of the area for crop production as PET is greater than rainfall in all months (Figure 1b).

\section{Survey 1}

Ninety-four farmers (55 men and 39 women) were sampled at random using a list of farmers compiled by the Agritex (Department of Agricultural Technical and Extension Services, Ministry of Agriculture) extension workers who were closely involved with this study. The fields of the sampled farmers were visited and information on standing crop characteristics was recorded by direct observation and by interview. The research instrument used was a semi-structured questionnaire which was designed to collect among others, the following information: types of crops and crop varieties growing in the farmers' fields, morphological and agronomic characteristics of varieties grown, size of land occupied by each crop/crop variety, methods of planting (e.g. broadcast/row, sole/mixed), source of seed, reasons for farmers' variety preferences (including gender differences), plant population densities, crop spacing, crop establishment and frequency of replanting.

Length of season a crop takes to maturity was defined as short (up to 100 days), medium (up to 120 days) and long season (up to 150 days) in sorghum and short (up to 140 days), medium (up to 150 days) and long (greater than 150 days) in maize. Plant height was defined as short (less than $150 \mathrm{~cm}$ ), medium (up to $180 \mathrm{~cm}$ ) and tall (greater than $180 \mathrm{~cm}$ ) in sorghum and short (less than $250 \mathrm{~cm}$ ), medium (up to $300 \mathrm{~cm}$ ) and tall (greater than $300 \mathrm{~cm}$ ) in maize. Particle size was defined as small $(15 \mathrm{~cm})$, medium $(20 \mathrm{~cm})$ and large $(30 \mathrm{~cm})$.

The survey was carried out in March 1996 when all varieties had passed the soft dough stage which made identification easier. In fields with intercrop/mixed varieties, population densities were recorded noting the separate and combined plant population. Size of each field was estimated by the farmer and the researcher. However, farmers' estimation of farm size is known to be unreliable, not because they wish to deceive but because they simply do not know. Therefore, proxy variables such as seeding rates, time taken for ploughing, planting, thinning, transplanting and weeding were used to estimate farm size. Visual assessment of stand establishment was done by the interviewer, supplemented by plant population density per unit area derived from quadrat sampling. A one square metre quadrat 


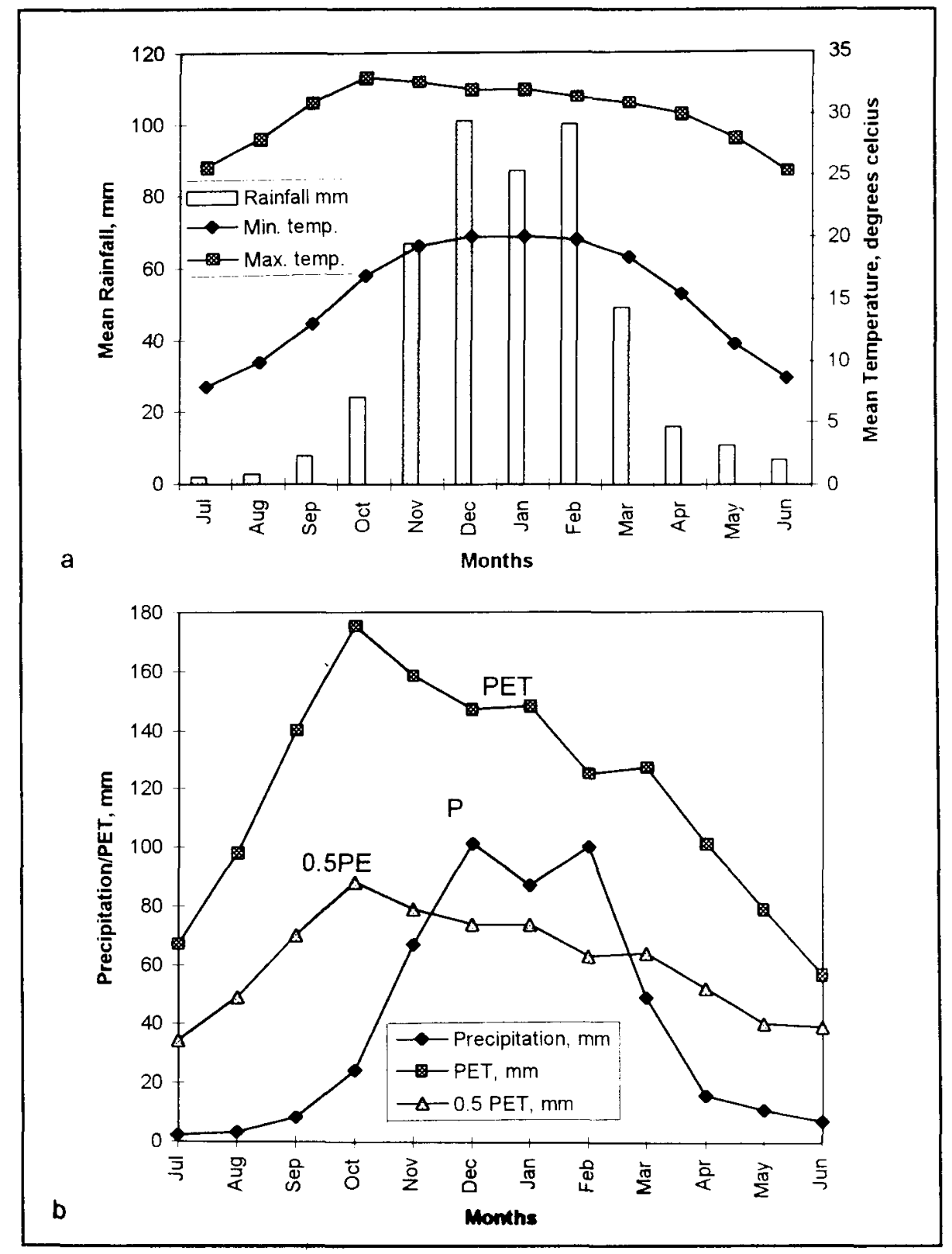

Figure 1: Mean monthly temperature and rainfall (a), and rainfall and potential evapotranspiration (PET) (b) for Middle Save, Zimbabwe, 1954 to 1984. 
was used. Ten quadrats per field were sampled at random and the number of plants within the quadrat was counted and expressed per ha.

\section{Survey 2}

A subset of 60 farmers ( 15 from each of the four villages; 37 men and 23 women) was sampled at random (using the same list of farmers used in the first survey obtained from extension staff) and asked to provide information on farming practices likely to affect crop establish-ment. The research instrument used again wasa questionnaire which was designed to collect data on farmers' agronomic practices and stand establishment problems. Information on farmers' practices collected included the following: crops grown, time of sowing, method of planting (e.g. sole or mixed), operation methods (farmers were asked whether they plough their fields before hand, broadcast/plough, dig/plant or plough/plant in rows), seeding rates, spacing, number of seeds per planting station, depth of planting, crop establishment problems, whether farmers soak their seed or transplant their seedlings, major pests affecting crop establishment and methods of storage of seed for next season. In the first survey, it was found out that the majority of the farmers used traditional unimproved varieties. In this survey the researchers were keen to find out how farmers handle their seed for planting in the next season since poorly stored seed can have an effect on germination per cent, hence crop establishment.

\section{Results}

\section{Survey 1}

The main crops grown in the study area were sorghum, maize and sunflower by 94.36 and 15 per cent of the respondents, respectively (Table 1). There was no pearl millet grown in the area during the survey season. Minor crops were intercropped with both maize and sorghum. Eighty-three per cent of the farmers grew cucumbers, 70 per cent grew watermelons, 35 per cent grew cowpeas and 14 per cent grew gourds in intercrop with sorghum. Maize was intercropped with cucumbers, watermelons, cowpeas and gourds by $85,65,33$ and 12 per cent of the farmers, respectively.

Table 1: Main crops grown by a sample of 94 farmers during the 1995/96 season in Musikavanhu Communal Area, Zimbabwe.

\begin{tabular}{|c|c|c|c|c|c|c|}
\hline \multirow[b]{2}{*}{ Crop } & \multirow[b]{2}{*}{ No of fields } & \multirow[b]{2}{*}{$\begin{array}{l}\% \text { of farmers } \\
\text { growing crop }\end{array}$} & \multicolumn{4}{|c|}{ Land devoted to crop (ha) } \\
\hline & & & Total & $\begin{array}{c}\text { Mean } \\
\text { farmer-1 crop-1 }\end{array}$ & SD & $\begin{array}{l}\% \text { of } \\
\text { total }\end{array}$ \\
\hline Sorghum & 88 & 94 & 230 & 1.5 & 1.0 & 82 \\
\hline Maize & 34 & 36 & 34 & 1.0 & 0.8 & 12 \\
\hline Sunflower & 14 & 15 & 15 & 1.1 & 1.2 & 7 \\
\hline Total & 136 & & 279 & & & 100 \\
\hline
\end{tabular}


Table 2: Sorghum, maize and sunflower cultivars grown by farmers in Musikavanhu Communal Area during the 1995/96 cropping season.

\begin{tabular}{|c|c|c|c|c|}
\hline \multirow[b]{2}{*}{ Variety } & \multirow[b]{2}{*}{ No. of fields } & \multirow[b]{2}{*}{$\%$ of farmers } & \multicolumn{2}{|c|}{ Land devoted to each variety } \\
\hline & & & Total (ha) & $\%$ of total land \\
\hline \multicolumn{5}{|l|}{ Sorghum } \\
\hline Short Mutode* & 59 & 63 & 104 & 37.3 \\
\hline Chihumani* & 36 & 38 & 56 & 20.1 \\
\hline Muchayeni ${ }^{\star}$ & 24 & 26 & 33 & 11.8 \\
\hline Chimariya* & 9 & 10 & 11 & 3.9 \\
\hline Tall Mutode & 7 & 7 & 6 & 2.2 \\
\hline Chitichi & 6 & 6 & 6 & 2.2 \\
\hline Red Swazi & 5 & 5 & 5 & 1.8 \\
\hline Chidhomeni & 3 & 3 & 1 & 0.4 \\
\hline Chichayeni & 2 & 2 & 3 & 1.1 \\
\hline Chimhondo & 1 & 1 & 2 & 0.7 \\
\hline Dehwe & 1 & 1 & 3 & 1.1 \\
\hline \multicolumn{5}{|l|}{ Maize } \\
\hline CG $4585^{\star}$ & 26 & 28 & 29 & 10.4 \\
\hline R 201 & 3 & 3 & 2 & 0.7 \\
\hline PAN 473 & 3 & 3 & 2 & 0.7 \\
\hline CG 4141 & 1 & 1 & 0.5 & 0.2 \\
\hline \multicolumn{5}{|l|}{ Sunflower } \\
\hline Local* & 13 & 14 & 14 & 5.0 \\
\hline Msasa & 1 & 1 & 1 & 0.4 \\
\hline
\end{tabular}

* grown by 10 per cent or more of the 94 farmers sampled.

Eleven varieties of sorghum were found growing in farmers' fields, although only four were grown by more than 10 per cent of farmers (Table 2). There was little use of improved sorghum varieties in the area although Chihumani is a locallymaintained version of an improved variety, SV-2. Although farmers grew four varieties of maize, by far the most common genotype was CG 4585 , seed of which had been distributed by Government as part of a drought relief package. Almost all sunflower was grown from farm-saved seed of unknown identity. Morphological and agronomic characteristics of the varieties grown by farmers during 1995/96 season are listed in Table 3.

The reasons for farmers' variety preferences are listed in Table 4. Early maturity was very important to farmers because shorter duration varieties often avoided drought conditions. Good taste in sorghum was usually associated with longer duration and white varieties like Muchayeni and Chichayeni. The earlymaturing and tasty Chihumani was an exception. Short Mutode and Chimariya 
Table 3: Morphological and agronomic characteristics of the cultivars grown by farmers during the 1995/96 cropping season in Musikavanhu Communal Area, Zimbabwe.

\begin{tabular}{|c|c|c|c|c|c|}
\hline \multirow[b]{2}{*}{ Variety } & \multirow[b]{2}{*}{ Grain colour } & \multirow{2}{*}{ Particle size } & \multicolumn{3}{|c|}{ orphological \& agronomic characteristics } \\
\hline & & & Season length & Plant height & Main use \\
\hline \multicolumn{6}{|l|}{ Sorghum } \\
\hline Short Mutode & red brown & large compact & short & short & beer \\
\hline Chihumani & cream white & large compact & short & short & sadza \\
\hline Muchayeni & chalky white & large lax & long & tall & sadza \\
\hline Chimariya & light brown & large compact & short & medium & sadza \\
\hline Tall Mutode & dark red brown & med. compact & medium & tall & beer \\
\hline Chitichi & chalkly white & med.compact & short & short & sadza \\
\hline Red Swazi & light brown & med.compact & short & short & beer \\
\hline Chidhomeni & pale white & large compact & short & short & sadza \\
\hline Chichayeni & pale white & med. compact & short & short & sadza \\
\hline Chimhondo & light brown & med. compact & medium & tall & sadza \\
\hline Dehwe & chalky white & small compact & medium & tall & sadza \\
\hline Maize & & grain size & & & \\
\hline CG 4585 & white & medium flat & short & medium & sadza \\
\hline R 201 & white & large flat & short & medium & sadza \\
\hline PAN 473 & white & medium flat & short & short & sadza \\
\hline CG 4141 & white & small flat & short & medium & sadza \\
\hline \multicolumn{6}{|l|}{ Sunflower } \\
\hline Local & black & large & short & medium & sale \\
\hline Msasa & black & large & short & medium & sale \\
\hline
\end{tabular}

(both red varieties high in tannins) were popular with male farmers because they were early maturing, were suitable for brewing beer and were not susceptible to attack by birds. Women, however, were influenced more by taste, storage and food preparation characteristics.

All sorghum and most sunflower was broadcast (Table 5) whereas most maize was row-planted with resultant population densities generally 35 per cent in excess of the 22000 plants ha ${ }^{-1}$ recommended for the area by Nyamudeza (1996). Mean plant population densities measured by quadrat sampling and expressed per ha are shown in Table 6 . All sorghum population means were below 66000 plants per ha recommended by Nyamudeza (1993), except Red Swazi which was 16 per cent above the recommended population. Gap-filling in sorghum was very common, with farmers re-sowing up to four times. Figure 2 shows that of the fields with mixed sorghum varieties only 3.4 per cent were initially sown with more than one variety and there was a linear relation $\left(y=0.579+1.08 x, R^{2}=0.73 ; n=119\right)$ between frequency of re-sowing and the 


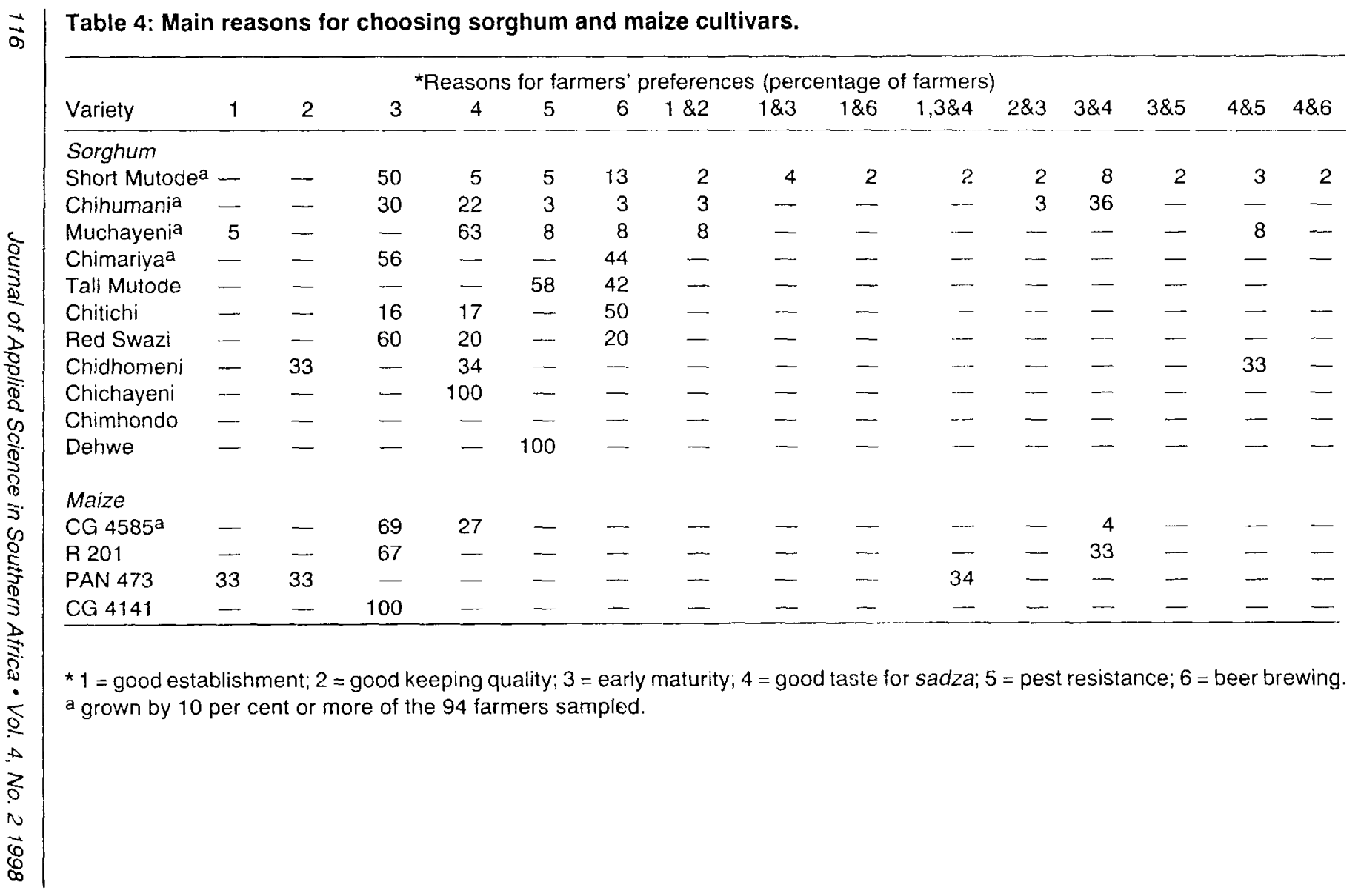


Table 5: Planting method and final plant spacings of crops grown by farmers during the 1995/6 cropping season in Musikavanhu Communal Area,

Zimbabwe.

\begin{tabular}{|c|c|c|c|c|c|c|}
\hline \multirow[b]{2}{*}{ Variety } & \multicolumn{2}{|c|}{$\begin{array}{c}\text { Planting method } \\
\text { (Percent of farmers) }\end{array}$} & \multicolumn{4}{|c|}{ Mean plant spacing (row crops only) } \\
\hline & B/cast & Row & $\begin{array}{l}\text { Inter-row } \\
\text { (cm) }\end{array}$ & SD & $\begin{array}{c}\text { In-row } \\
(\mathrm{cm})\end{array}$ & SD \\
\hline $\begin{array}{l}\text { Sorghum } \\
\text { All varieties }\end{array}$ & 100 & 0 & - & - & - & - \\
\hline $\begin{array}{l}\text { Maize } \\
\text { CG } 4585\end{array}$ & 38 & 62 & 65 & 15.2 & 55 & 16.0 \\
\hline $\begin{array}{l}\text { R } 201 \\
\text { PAN } 473 \\
\text { CG } 4141\end{array}$ & $\begin{array}{r}100 \\
0 \\
33\end{array}$ & $\begin{array}{r}0 \\
100 \\
67\end{array}$ & $\begin{array}{l}- \\
82 \\
77\end{array}$ & $\begin{array}{r}-\overline{2} \\
23.0 \\
0.6\end{array}$ & $\begin{array}{l}- \\
59 \\
52\end{array}$ & $\begin{array}{r}- \\
30.3 \\
7.8\end{array}$ \\
\hline $\begin{array}{l}\text { Sunflower } \\
\text { Local } \\
\text { Msasa }\end{array}$ & $\begin{array}{r}85 \\
0\end{array}$ & $\begin{array}{r}15 \\
100\end{array}$ & $\begin{array}{l}81 \\
-\end{array}$ & $\begin{array}{r}27.0 \\
-\end{array}$ & $\frac{45}{-}$ & $\begin{array}{r}4.4 \\
-\end{array}$ \\
\hline
\end{tabular}

Table 6: Mean plant population densities per hectare in sole crops during the 1995/96 cropping season in Musikavanhu Communol Area, Zimbabwe.

\begin{tabular}{|c|c|c|c|c|c|c|}
\hline \multirow[b]{2}{*}{ Variety } & \multirow[b]{2}{*}{ Mean } & \multirow[b]{2}{*}{ SD } & \multirow[b]{2}{*}{$n$} & \multicolumn{3}{|c|}{ Mean plant population (ha) } \\
\hline & & & & Maximum & Median & Minimum \\
\hline Short Mutode & 56504 & 41951 & 390 & 130000 & 45000 & 26000 \\
\hline Chihumani & 48056 & 28463 & 60 & 66000 & 43500 & 33000 \\
\hline Muchayeni & 46333 & 20664 & 60 & 66000 & 43500 & 33000 \\
\hline Tall Mutode & 54500 & 31431 & 60 & 88000 & 52500 & 32000 \\
\hline Red Swazi & 76803 & 49875 & 50 & 12400 & 67000 & 28000 \\
\hline Chimariya & 39750 & 14049 & 49 & 50000 & 37000 & 35000 \\
\hline Chitichi & 49500 & 24810 & 20 & 56000 & 49500 & 43000 \\
\hline Chimhondo & 35000 & 21731 & 10 & 1 field only & - & - \\
\hline \multicolumn{7}{|l|}{ Maize } \\
\hline CG 4585 & 38312 & 14989 & 260 & 59000 & 38000 & 24000 \\
\hline R 201 & 37750 & 10833 & 30 & 46000 & 35000 & 32000 \\
\hline PAN 473 & 35969 & 11246 & 30 & 37000 & 36000 & 35000 \\
\hline CG 4141 & 39000 & 12867 & 10 & 1 field only & - & - \\
\hline \multicolumn{7}{|l|}{ Sunflower } \\
\hline Local & 53483 & 27966 & 130 & 93000 & 50000 & 32000 \\
\hline Msasa & 59000 & 20790 & 10 & 1 field only & - & - \\
\hline
\end{tabular}




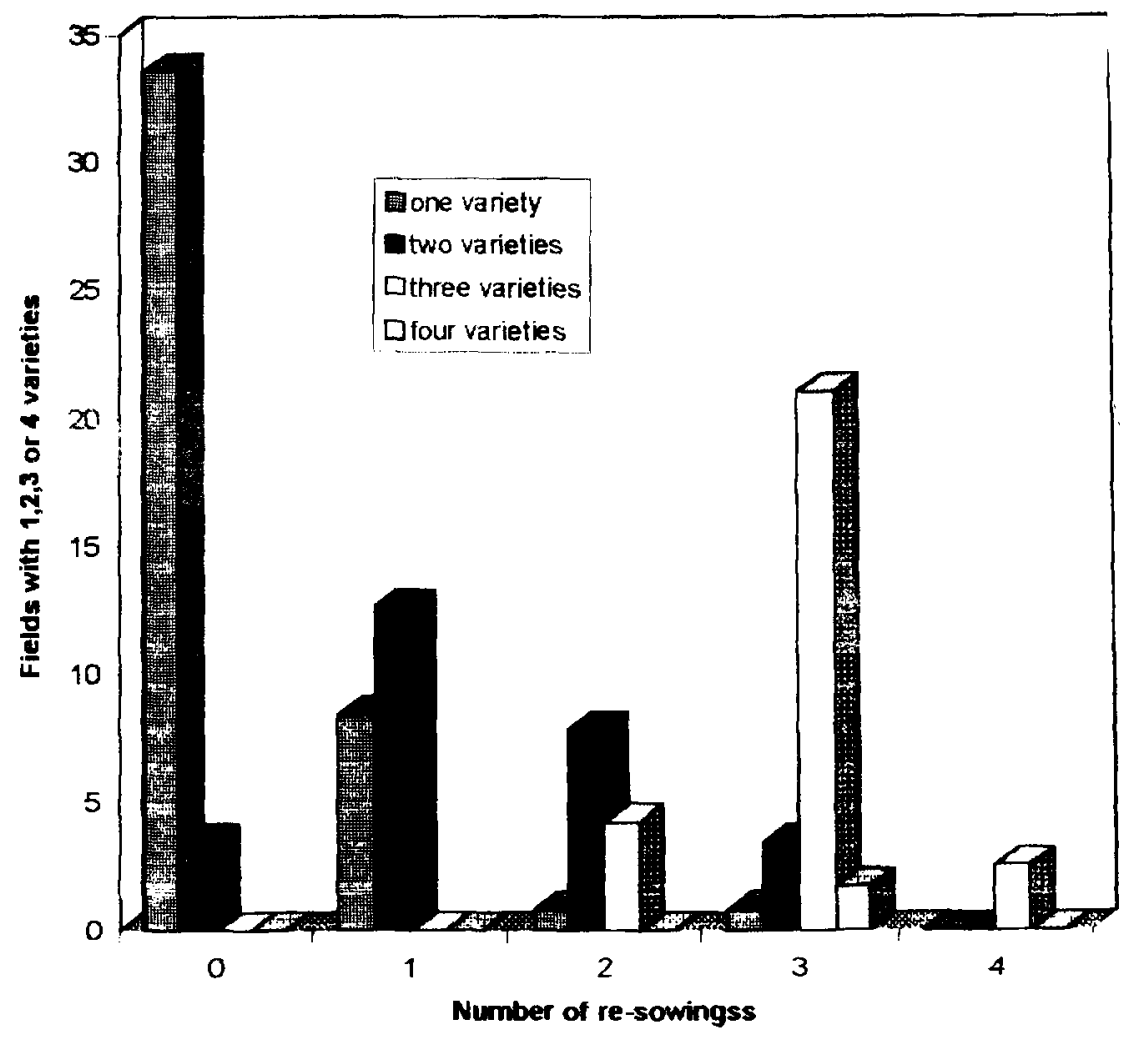

Figure 2: Relation between the number of sorghum varieties field-1 and the number of times the field was re-sown. Total sample was 119 fields with either Short Mutode, Chihumani or Muchayeni as the initial variety sown (see Table 2).

eventual number of varieties grown. Farmers in the study area reported that they mixed sorghum varieties because they were unable to obtain replacement seed of their preferred cultivars if they failed to establish and other, less preferred cultivars had to be used. However, even in fields where varieties were mixed, combined plant populations ranged from 26000 to 94000 plants/ha with a mean of 47000 plants/ha well below the recommended optimum of 66000 plants/ha.

Although farmers replant more than once (Table 7 and Figure 2), most of them did not achieve a reasonable plant stand as plant population ranged from as low as 26000 to 130000 plants per hectare (Table 6) in sorghum. 
Table 7: Percentage of farmers who replant between 0 and 4 times during the 1995-96 cropping season in Musikavanhu Communal Area, Zimbabwe.

\begin{tabular}{|c|c|c|c|c|c|}
\hline & \multirow[b]{2}{*}{ Number of times: } & \multicolumn{4}{|c|}{ Percentage Farmers who replant } \\
\hline & & 1 & 2 & 3 & 4 \\
\hline \multicolumn{6}{|l|}{ Sorghum } \\
\hline Short Mutode & 34 & 25 & 10 & 28 & 3 \\
\hline Chihumani & 43 & 14 & 14 & 29 & 0 \\
\hline Muchayeni & 33 & 21 & 17 & 25 & 4 \\
\hline Chimariya & 22 & 30 & 6 & 31 & 11 \\
\hline Tall Mutode & 60 & 0 & 20 & 0 & 20 \\
\hline Chitichi & 67 & 33 & 0 & 0 & 0 \\
\hline Red Swazi & 50 & 50 & 0 & 0 & 0 \\
\hline Chidhomeni & 0 & 100 & 0 & 0 & 0 \\
\hline Chichayeni & 22 & 0 & 22 & 44 & 12 \\
\hline Chimhondo & 17 & 16 & 0 & 50 & 17 \\
\hline Dehwe & 0 & 100 & 0 & 0 & 0 \\
\hline \multicolumn{6}{|l|}{ Maize } \\
\hline CG 4585 & 35 & 31 & 19 & 15 & 0 \\
\hline R 201 & 100 & 0 & 0 & 0 & 0 \\
\hline PAN 473 & 670 & 33 & 0 & 0 & \\
\hline CG 4141 & 0 & 0 & 100 & 0 & 0 \\
\hline \multicolumn{6}{|l|}{ Sunflower } \\
\hline Local & 0 & 0 & 0 & 100 & 0 \\
\hline Msasa & 69 & 15 & 8 & 0 & 0 \\
\hline
\end{tabular}

\section{Survery 2}

Some of the common land preparation and planting methods used by farmers in Musikavanhu Communal $\wedge$ rea are shown in Table 8 . All farmers practised both dry planting and wet planting (i.e. planting after the rains) in sorghum whereas maize and sunflower were planted after the rains. Comparison of Table 5 and 8 shows that farmers in the second survey indicated that they sometimes plant their sorghum in rows, but observations in the field indicated that, in 1996, all sorghum was broadcast. Farmers use a combination of planting methods according to their individual curcumstances and those who used hoes (to dig planting holes) indicated shortage of draught power.

The second survey revealed that farmers plant their sorghum, maize and sunflower at an average depth of 8,11 and $7 \mathrm{~cm}$ with standard deviations of 4,5 and 4 , respectively. Farmers who plant their sorghum, maize and sunflower per station indicated seeding rates of $10-30,1-3$ and $3-5$ seeds per planting station with means of 17,1 and 4 and standard deviations of $11,0.6$ and 4 , respectively. 
Table 8: Common land preparation and planting methods used by farmers in Musikavanhu Communal Area, Zimbabwe.

\begin{tabular}{lrcc}
\hline & & \multicolumn{2}{c}{ Percentage Positive Respondents } \\
\cline { 3 - 4 } Practices & Maize & Sorghum & Sunflower \\
\hline Plough before hand & 26 & 23 & 24 \\
Broadcast plough & 15 & 55 & 28 \\
Plough plant (rows) & 72 & 30 & 56 \\
Dig planting hole & 37 & 42 & 36 \\
Broadcast and weed & 7 & 27 & 4 \\
Thinning & 64 & 100 & 92 \\
Dry planting & 0 & 100 & 0 \\
\hline
\end{tabular}

Table 9: a) Incidence of poor stand establishment, b) reasons for it, c) use of methods for improving it.

\begin{tabular}{lccc}
\hline \multirow{2}{*}{ Question } & \multicolumn{3}{c}{ Percentage of Respondents } \\
\cline { 2 - 4 } & Maize & Sorghum & Sunflower \\
a) Poor stands? & 93 & 95 & 87 \\
b) Reasons? & & & \\
Low moisture & 65 & 73 & 74 \\
Bad seed & 13 & 18 & 22 \\
$\quad$ Pests (Hodotermis spp.) & 50 & 42 & 17 \\
& & & 4 \\
c) Use improvemetns? & 37 & 2 & 13 \\
\hline
\end{tabular}

Poor stand establishment was reported by 93,95 and 87 per cent of farmers in maize, sorghum and sunflower, respectively (Table 9). The major reasons cited for this in all three crops were low soil moisture at sowing time, pests (especially Hodotermis mosambicus L.) and poor seed quality. Thirty-seven per cent of farmers reported soaking maize seed sometimes overnight before sowing, although this was more usually only done if sowing was delayed following a planting rain. Only one farmer reported soaking sorghum seed, while two said that they had tried soaking sunflower. In contrast, 97 per cent of farmers reported trans-planting sorghum using thinnings whereas only 15 per cent and 13

per cent transplanted maize and sunflower, respectively.

Most farmers ( 90 per cent) select seed after harvesting for planting next season but only 52 per cent reported dressing their sorghum seeds with chemicals. Seed for 
planting next season is prone to damage by pests, reducing their quality and germination per cent which can adversely affect stand establishment.

\section{Discussion}

Sorghum, maize and sunflower were the most important crops in the study area. Minor crops like cowpeas, pumpkins, watermelons, cucumbers and gourds were commonly intercropped with sorghum and maize. They are clearly important to farmers and are eaten green either as vegetables, as desserts or when farmers are working in the fields. The role of these minor crops in semi-arid areas of Zimbabwe has been described elsewhere (Mazvimavi et al., 1994) and discussion here is confined to the three main crops. It is somewhat surprising that no pearl millet was grown in the study area as this crop can be observed in fields in the Tanganda area to the north. When questioned, farmers attributed the absence of pearl millet in the area to traditional beliefs reinforced by the views of local chiefs. The chiefs do not allow their people to grow pearl millet because the ancestral spirits 'guiding' the chiefs do not tolerate pearl millet. It is alleged that if these chiefs eat any pearl millet product they become ill. These socio-cultural constraints are at odds with views on the agro-ecological suitability of pearl millet for the area. The crop is considered to be more drought tolerant than either maize or sorghum (Kassam and Kowal, 1975)

Eleven varieties of sorghum were recorded with most farmers growing more than one variety in the same field. Sometimes mixing of early and late maturing varieties was planned but usually mixtures resulted from the need to re-plant or fill gaps in a patchy stand. The first gap filling was usually done with the same variety but in subsequent gap fillings the farmers resorted to other sorghum varieties because of lack of seed. Not only does inappropriate plant population lead to low yields but to food insecurity at household level.

Only four of the sorghum varieties were grown by more than 10 per cent of the farmers and only Chihumani was an improved variety, and then not in a pure form. This is in general agreement with Oosterhout van (1992) who found out that, of the sorghum varieties grown in her study sites (Musikavanhu, Gokwe and Siabuwa), about half were grown by only a small proportion, often less than 10 per cent, of the farmers. Either improved sorghum germplasm is not deemed suitable by farmers or it is not reaching them on a regular basis. Certainly the reasons for choosing varieties cited in this study do not include yield-related characteristics and early maturity seems to be particularly important. Mazvimavi et al, (1994) have also reported that 36 per cent of the respondents in their survey in Chiredzi district, an area with similar climate, preferred early maturing varieties. It is interesting to speculate on the consequences for crop diversity in the area if stand establishment were to be improved substantially. Data in Figure 2 and Table 7 suggest that reducing the frequency of re-sowing might reduce the number of varieties grown together in the same field, although differences in preference between farmers could maintain diversity in the area as a whole. 
Maize varieties grown during the $1995 / 96$ season were obtained from the government as part of the drought recovery programme and, in this respect, this season (1996/97) may be atypical. Maize has become a preferred food staple in Zimbabwe even in low rainfall areas like Musikavanhu. Farmers seem to be willing to buy and sow hybrid maize seed, even in this high risk, semi-arid environment, and the high perceived value of maize is evident in the care taken to plant a large proportion of it in rows in contrast to sorghum which is entirely broadcast. Mbwanda and Rohrbach (1989) suggest that the increase in smallholder maize production is due to institutional and technological interventions introduced by the government. Much debate has surrounded the widespread shift from more drought tolerant small grains to maize in semi-arid cropping systems, a development made possible by the availability of relatively short-season maize hybrids, for example R 200, R 201 (Mazvimavi etal., 1994). Several authors (for example Rukovo and Gwitira, 1994; van Oosterhout, 1996) have suggested the distribution of small grains instead of maize in drought-susceptible areas, and it is interesting to note that in the study area sorghum still occupied most of the crop land - perhaps a reflection of farmers' experience and pragmatism in a harsh environment.

Land preparation may have an effect on subsequent crop establishment and Chiduza et al (1995) have noted poor moisture infiltration due to localised and shallow land preparation using a hoe. Only planting stations are tilled when using a hoe and weeds are often present. Timeliness of land preparation can have important effects on soil moisture conservation, mineralisation of crop residues, weed growth, and most significantly on planting time and the success of crop establishment (Stroud, 1985; Rowland and Whiteman, 1993).

The diversity of farmer perceptions of poor stand establishment is emphasised by the data in Table 9 reinforced by observed data in Tables 6 and 7 and Figure 2 . Not only are farmers acutely aware of the problem and understand the main reasons for it, they have also developed appropriate responses. Ninety-seven per cent of farmers reported transplanting sorghum, using thinnings from overcrowded parts of the field. Conditions for successful transplanting were well known-moist soil and plants of a particular size. Thinnings were used both to fill gaps and to plant extra areas, particularly if good early rains persisted into the middle of the season. The physiology of transplanting sorghum is not well understood, particularly its merits relative to re-sowing and the labour involved. In contrast to sorghum, farmers did not transplant maize or sunflower to any great extent. Of the three crops only sorghum readily produces tillers and has the developmental plasticity to respond succesfully to bare-root transplanting, although transplanting nurserygrown seedlings of maize has proved feasible on wetland soils, for example in Vietnam (Uy and Marathé, 1996).

The willingness of a significant proportion of farmers to soak maize seed is encouraging (Table 9) although closer questioning showed that this was only done to 'catch up' if a sowing opportunity had been missed. Farmers did not consider it 
worthwhile to soak maize seed before suwing under optinal conditions and they hardly considered soaking sorghum seed at all. This may be a missed opportunity because Harris (1996) has shown that a major factor influencing crop establishment in sorghum is the rate of germination and emergence and that soaking seed or 'on-farm priming' for 8 to 10 hours before all sowings can markedly improve establishment and early growth. Similar results were obtained after priming maize for up to 24 hours (Harris, unpublished data) although preliminary work with sunflower suggests that it does not respond well to seed priming. Research is under way to develop and evaluate this technology further in collaboration with Zimbabwean farmers.

\section{Conclusion}

Poor crop establishment is a major factor affecting crop production in the semi-arid areas of Zimbabwe. A large per centage of farmers cited the problem in this study and this conclusion is supported by population densities observed in farmers' fields. Sorghum diversity in the area is linked to the success or failure of early plantings and improved crop establishment might reduce diversity, at least within fields. The problem of stand establishment is not confined to the south east lowveld alone but has been reported by several authors from other semi-arid areas of Zimbabwe. Farmers have developed appropriate responses - soaking maize seed and transplanting young sorghum plants - in order to improve crop stands. There is need to develop further agronomic practices that will improve crop establishment in semi-arid areas of Zimbabwe and the best step towards a technology better suited to the majority of the smallholders is the use or improvement of existing indigenous technology. Seed priming (soaking) has been used elsewhere with other crops and locally by few farmers and can be used in maize and sorghum to improve crop establishment. Transplanting sorghum has never been explored by researchers locally to see its effects on establishment, growth and yield performance, yet the practice has been going on for a long time. Thus, current farming practices provide a point of departure for developing and refining technologies to address one of the major reasons for production shortfalls in the semi-arid smallholder sector.

\section{ACKNOWLEDGEMENTS}

The authors thank the AGRITEX extension staff of the respective villages, all farmers who cooperated in the study and all colleagues who assisted in data collection. This document is an output from a project (Plant Sciences Research Programme project R6395) funded by the UK Department for International Development (DFID) administered by the Centre for Arid Zone Studies (CAZS) for the benefit of developing countries. The views expressed are not necessarily those of DFID. 


\section{REFERENCES}

Anderson, 1. P., Brinn, P. J., Moyo, M. and Nyamwanza, B. 1993 Physical resource inventory of the communal lands of Zimbabwe - An overview. NRI Bulletin 60. Natural Resources Institute, Chatham, UK. $186 \mathrm{pp}$.

BeEts, W. C. 1990 Raising and Sustaining Productivity of Smallholder Farming Systems in the Tropics: A Hand Book of Sustainable Agricultural Development. AgBe Publishing. 738 pp.

ChIDUZA, C. 1987 On-farm evaluation of sorghum (Sorghum bicolor (L.) Moench) varietis in the Sebungwe Region of Zimbabwe. MPhil thesis, Department of Soil Science and Agricultural Engineering, University of Zimbabwe. $140 \mathrm{pp}$.

Chiduza, C. 1993 An agronomic evaluation of ratooning and plant spacing in sorghum and comparative performance with maize and pearl millet in the northern Sebungwe. Zimbabwe. DPhil thesis, Department of Crop Science, University of Zimbabwe. 310 pp.

Chiduza, C., WadDington, S. R. AND MARIGA, I. K. 1994. Grain yield and economic performance of open-pollinated varieties and released hybrids of maize in a remote semi-arid area of Zimbabwe. Zimbabwe Journal of Agricultural Research, 32: 33-43.

Chiduza, C., Waddington, S. R. and Rukuni, M. 1995 Evaluation of sorghum technologies for smallholders in a semi-arid region of Zimbabwe (Part 1): Production practices and development of an experimental agenda. Journal of Applied Science in Southern Africa, 1: 1-10

ChIVASA, W. 1995 Survey of sunflower (Helianthus annus (L.)) production constraints and comparative performance with maize (Zea mays (L.)) and sorghum (Sorghum bicolor (L.)) in Matibi II communal area of Zimbabwe. BSc. Agriculture Honours Project, Department of Crop Science, University of Zimbabwe. 75 pp.

FARMING SYSTEM RESEARCH UNIT (FSRU). 1994 Coping with risk and uncertainty in Zimbabwe's communal lands. Summary report, Department of Research and Specialist Services, Ministry of Lands, Agriculture and Water Development, Harare, Zimbabwe.

Hafris, D. 1992. Seedbeds and crop establishment, in Kronen M. (ed.), Proceedings of the Second Annual Scientific Conference of the SADCC/ODA Land \& Water Management Programme, pp. 165-172. P. Bag 00108, Gaborone, Botswana.

HaRRIS, D. 1996 The effects of manure, genotype, seed priming, depth and date of sowing on the emergence and early growth of Sorghum bicolor (L.) Moench in semi-arid Botswana. Soil \& Tillage Research, $40(1 / 2)$; 73-88.

Kassam, A. H. AND KowaL, J. M. 1975 Water use, energy balance and growth of gero millet at Samaru, Northern Nigeria, Agric. Met. 15: 333-342.

LANDSBERG, J. T. 1964 Agronomic investigation at Matopos Research Station and their relation to the low rainfall areas of $\mathrm{S}$. Rhodesia. MSc in Agriculture Seminar $V$., Department of Agronomy, Faculty of Agriculture, University of Natal, Natal.

MBWANDA, C. AND RohrbaCH, D. A. 1989 Small grain markets in Zimbabwe: The food security implications of national policy in Mudimu, G. and Bernsten, R. H. (eds.) Household and National Food Security in Southern Africa. Proceedings of the Fourth Annual Conference on Food Security Research in Southern Africa, 1988. UZ/MSU Food Security Research Project, Department of Agricultural Economics and Extension, Harare.

Mazvimavi, K., Rukuni, T., Guveya, E. and DzingiaAi, V. 1994 A comparative analysis of the demand for sorghum in the food systems of the semi-arid areas of Chiredzi District. 33 pp. 
Nyamudeza, P. 1993 The effects of growing sorghum bicolor (L.) in furrows and on the flat at three row widths and three populations in a semi-arid region of Zimbabwe. 1. Grain yield and yield components. Zimbabwe Journal of Agricultural Research. 31: 1-10.

NyamudezA, P. 1996 Agronomic practices for the low rainfall Natural Region $V$ of Zimbabwe. in: Water for Agriculture: Current Practices and Future Prospects. Universty of Zimbabwe/ Zimwesi Workshop, 11-13 March 1996. Harare, Zimbabwe. pp 1-21.

OLVER, R. C. 1988 Zimbabwe maize breeding program. pp 34-43 in Gelaw, B. (Ed.) Towards Self Sufficiency. Proceedings of the Second Eastern, Central and Southern Africa Regional Maize Workshop, March 15-21, 1987, Harare, Zimbabwe. CIMMYT.

OKONWO, J.C. AND VANDERLIP, R.L. 1985 Effect of cultural treatment on quality and subsequent performance of pearl millet seed. Field Crops Research, 11: 161-170.

OOSTERHOUT VAN, S A. M. 1992 The biosystematics and ethenobotany of sorghum bicolor in Zimbabwe. DPhil thesis, Department of Biological Sciences, University of Zimbabwe, Harare, Zimbabwe.

OOSTERHOUt VAN, S. A. M. 1996a Coping Strategies of Smallholder Farmers With Adverse Weather Conditions Regarding Seed Deployment of Small Grain Crops During the 1994 to 1995 Cropping Season in Zimbabwe. Vol. 1-3, SADC/GTZ, Harare, Zimbabwe.

Oosterhout VAN S. A.M. 1996b What does in situ conservation mean in the life of a small-scale farmer? Examples from Zimbabwe's communal areas. pp 35-52. In: Sperling. S. \& Loevinsohn, M. (Eds. Using Diversity, Enhancing and Maintaining Genetic Resources On-Farm. Proceedings of a workshop held 19-21 June, 1995, New Delhi, India. IDRC, Canada.

Rowland, J.R.J and Whiteman, P. 1993 Principles of dryland farming. pp 68-94 in Rowland J. R. J. (Ed.) Dryland Farming in Africa. Macmillan Press Ltd. Hong Kong.

Rukovo, A. AND GWITIRA, J. 1994 Small grains policy in Zimbabwe under Economic Structura! Adjustment. Report of Study for ENDA Zimbabwe, Harare.

Stroud, A. 1985 Finding solutions to tillage problems: A case study from the semi-arid areas of Eastern Province, Kenya, in Proceedings of the Tenth East African Weed Science Society Conference, 27-31 May 1985. Department of Crop Science, University of Nairobi, P.O. Box 30197, Nairobi.

UY, T.H. AND MARATHEE, J.P.1996 Transplanting maize on wetland: A Technical manual based on a successful case-study in Viet Nam. FAO, Rome. 21 pp.

Vincent, V. and Thomas, R. G. 1960 An Agricultural Survey of Southern Rhodesia. Pant 1. Agroecological Survey. Government Printer. 124 pp.

WhitLow, J. R. 1980 Land use, population pressure and rock outcrops in the tribal areas of Zimbabwe. Zimbabwe Journal of Agricultural Research. 77: 3-11. 


\section{$U^{\text {NIVERSITY OF }}$ ZIMBABWE Publications}




\section{(c) (1) (9)}

This work is licensed under a

Creative Commons

Attribution - NonCommercial - NoDerivs 3.0 License.

To view a copy of the license please see:

http://creativecommons.ora/licenses/bv-nc-nd/3.0/ 